\title{
O EFEITO DO PAÍS DE ORIGEM DE PRODUTOS NA PERCEPÇÃO DE EXECUTIVOS FRANCESES E BRASILEIROS
}

\author{
THE EFFECT OF THE COUNTRY OF ORIGIN OF PRODUCTS IN THE PERCEPTION \\ OF FRENCH AND BRAZILIAN EXECUTIVES
}

Fernando Carvalho de Almeida

Faculdade de Economia, Administração e Contabilidade da FEA/USP

Hubert Drouvot

Institut d'Administration des Entreprises de Grenoble, Universidade Pierre Mendès France
Recebido em: 20/01/2009 Aprovado em: 05/06/2009

\section{RESUMO}

Esta pesquisa buscou explorar a percepção dos consumidores franceses e brasileiros quanto a produtos estrangeiros e, em particular, com relação ao produto brasileiro. A pesquisa se fundamenta na aplicação de um questionário de 20 questões com escala baseada em adjetivos bipolares, que procura medir a percepção do consumidor (NAGASHIMA, 1970). Constatou-se que os consumidores franceses e brasileiros percebem o produto brasileiro como bastante inferior aos produtos dos países desenvolvidos no que diz respeito à imagem e à qualidade. Esta percepção se aproxima bastante do que se observou quanto ao produto chinês. Observou-se, também, que o consumidor francês tem uma imagem estereotipada do produto brasileiro (por exemplo: café, carnaval, futebol, música/ dança, dentre os produtos mais lembrados), que não condiz com a realidade de desenvolvimento industrial do país. Concluiu-se que o Brasil tem um grande esforço a fazer para construir uma imagem externa mais condizente com sua realidade, bem como com seus interesses econômicos.

Palavras-chave: marketing, percepção do consumidor, país de origem do produto.

\section{ABSTRACT}

This research explores the French and Brazilian consumers perception related to foreign products and in particular regarding the Brazilian products. This research is based on the use of a questionnaire of 20 questions based on a bipolar scale that measures the consumers perception (NAGASHIMA 1970). It can be observed that French and Brazilian consumers perceive Brazilian products as being largely inferior than those of developed countries, in aspects like image and quality. This perception is observed as being very near of the opinion of French consumers in to Chinese products. The French consumer also has a stereotype of Brazilian products (products like coffee, carnival, soccer, music/dance among the most mentioned) that does not match with the reality of the industrial development of the country. The conclusion is that Brazil has a great effort to build an image abroad more in keeping with its reality as well as its economic interests.

Keywords: consumers, perception foreign products.

Endereços dos autores:

Fernando Carvalho de Almeida

Av. Prof. Luciano Gualberto 908 - sala G122 - 05508-900 - São Paulo - SP - e-mail: fcalmeida@usp.br

Hubert Drouvot

75 rue des Ayguinards, apto 15 - 38240 Meylan, França- e-mail: hubert.drouvot@iae-grenoble.fr 


\section{INTRODUÇÃO}

Nos últimos 40 anos, diversas pesquisas foram realizadas com o objetivo de identificar a percepção do consumidor diante de produtos fabricados em países estrangeiros. Estes estudos que relacionam país de origem à percepção do consumidor permitiram melhor compreender as atitudes do consumidor em diferentes países no tocante a produtos estrangeiros (será usada, daqui por diante, a sigla COO para substituir o termo em inglês country-of-origin). Os países estudados são os mais variados, tais como França, Alemanha, Japão, Estados Unidos, Itália ou Índia, Arábia Saudita, Marrocos, Nigéria, Taiwan e Coreia, dentre outros. Os primeiros estudos deste tipo (Shooler, 1965, apud Verlegh \& SteenKamp, 1999); ReIERSON, 1966; NAGASHIMA, 1970) constataram influências na avaliação dos consumidores em relação a produtos estrangeiros, identificando diferenças na opinião dos referidos consumidores, segundo o país de origem dos produtos.

O objetivo da presente pesquisa é avaliar as atitudes de executivos franceses e brasileiros com relação a produtos fabricados em particular no Brasil, mas também em outros países, como França, Itália, China, Alemanha, Japão e Estados Unidos. A presença de diferentes países permite comparar a visão do produto brasileiro em relação à dos produtos de outras nações. A exemplo de outros estudos sobre o tema (Roth \& Romeo, 1992; Mohamad, Ahmed \& TYEBKHAN, 2000; KIEN-Quoc, 2006), a amostra deste trabalho é composta de executivos e estudantes, estes em processo de formação em cursos de Administração na França e no Brasil. Apesar da grande incidência de pesquisas sobre COO, o número de estudos empíricos que dizem respeito às atitudes de consumidores de países desenvolvidos em relação a países em desenvolvimento é bastante limitado. Assim, a presente pesquisa preocupa-se em situar a imagem do produto brasileiro em relação a outros países que têm um papel expressivo no comércio mundial.

O tema em referência mostra-se essencial, pois a percepção do COO parece influenciar o comportamento dos consumidores em relação a produtos de origem estrangeira (REIERSON, 1966; NAGASHIMA, 1970; Lawrence, Marr \& Prendergast, 1992; Kamis \& NagaShima, 1995; Chéron \& Propeck, 1997 ; Kaynak \& Kara, 2002 etc.). De fato, em função de suas percepções, os consumidores podem dar maior preferência a produtos que provêm de certos países (os perfumes franceses, os sapatos italianos, os carros alemães etc.). No sentido oposto, as empresas de países que não se beneficiam de uma percepção favorável no âmbito industrial terão maior dificuldade de fazer frente à concorrência internacional.

O desenvolvimento do comércio internacional tem importância crescente para as economias atuais, e a imagem do país de origem pode ter influência significativa no desempenho do consumo de seus produtos no exterior.

Já há vários anos têm sido notadas profundas transformações pelas quais passou o Brasil no sentido de modernização. É possível constatar que estes progressos econômicos raramente são citados nos meios de comunicação franceses. Levy (2003), em seu livro O novo Brasil, preocupou-se em descrever todas estas evoluções em diversos setores de atividade.

Especificamente, qual a reação dos executivos e estudantes franceses em relação ao produto brasileiro? Por trás desta questão, transparece o conteúdo das informações percebidas por estes indivíduos sobre os aspectos econômicos do Brasil. Os resultados da pesquisa aqui proposta permitem verificar se o julgamento das pessoas questionadas integra a realidade da dimensão industrial do País ou se ela continua confinada numa visão estereotipada e folclórica do Brasil.

\section{LITERATURA SOBRE INFLUÊNCIA DO PAÍS DE ORIGEM}

Estima-se que existam entre 300 (ANDERSEN \& Chao, 2003) e 700 (PApadopoulos \& Heslop, 2002) trabalhos de pesquisa sobre país de origem na literatura acadêmica. É, segundo Peterson \& Jolibert (1995), o assunto mais tratado na literatura de pesquisa do consumidor até hoje. São mais de 40 anos de pesquisa desde que Dichter (1962, apud Verlegh \& SteENKAMP, 1999: 116) sugeriu que o país de origem de um produto deveria exercer uma "enorme influência na aceitação e no sucesso de um produto". O primeiro trabalho publicado foi o de Shooler (1965, apud VerLEGH \& SteENKAMP, 1999), que encontrou diferenças significativas na avaliação de produtos que, apesar de idênticos, só se diferenciavam quanto ao país de origem, especificado pelo rótulo made in. 
Os trabalhos que se seguiram exploraram diversos aspectos a respeito do tema país de origem (COO). Analisaram escalas de medidas, testaram variáveis, buscaram entender as relações entre variáveis, procuraram discutir de que modo o COO influencia o indivíduo na qualidade percebida do produto. Na medida em que o consumidor não tem informação sobre caraterísticas intrínsecas do produto, ou não tem como medilas ou avaliá-las, ele lança mão das características extrínsecas, como o COO (ZeithamL, 1988; INsCH, 2003).

O coO de um produto é a percepção de características intangíveis distintas de suas características físicas ou seus atributos intrínsecos (PHARR, 2005). A preocupação básica dos estudos sobre COO está associada à compreensão do comportamento do consumidor e ao entendimento dos fatores que influenciam a intenção de compra do consumidor (ANDERSEN \& ChAO, 2003). Trabalhos mais recentes têm focado aspectos multidimensionais do COO (INSCH \& McBride, 1998, 2004; ChaO, Wuhrer \& Werani, 2005).

As pesquisas realizadas sobre o tema abordaram as influências relacionadas a produtos em geral (NAGASHIMA, 1977), a classes de produtos (NAGASHIMA, 1970; WANG, 1978, apud NebeNZAHL et al., 2003), a produtos agrícolas (AURIER \& FORT, 2005), a tipos específicos de produtos (GAEDEKE, 1973; HesLOP, LIEFILD \& Wall, 1987 apud IsRael et al. 2003; Loureiro \& UMBERGER, 2003), a produtos de consumo (SCHOOLER, 1965 apud Verlegh \& Steenkamp, 1999; Lillis \& Naranya, 1974; Papadopoulos, Heslop \& Bamossy, 1990, apud Nebenzahl et al., 2003) e a produtos industriais (WHITE, 1979; ChASSIN \& JAFFE, 1979, 1987; CATtIN, Jolibert \& LOHNES, 1982; INSCH, 2003).

Alguns estudos buscaram tipologias de pesquisa sobre a influência do COO (Obermilller \& SPANGenBerg, 1989), ou procuraram avançar na formação de uma teoria sobre a influência do COO na percepção do consumidor (Gürhan-Canli \& Maheswaran, 2000b). A seguir, faz-se uma revisão da literatura sobre cada um destes aspectos.

\subsection{COO e avaliação do produto}

\section{COO como uma influência extrínseca}

Ahmed et al. (2004) destacaram a relação entre COO e avaliação do produto, afirmando que os consumidores tomam decisão sobre a qualidade de um determinado produto com base em um processo de aquisição, avaliação e integração das pistas (cues) de informações sobre ele. As pistas (cues) são definidas como todo estímulo de informação disponível para o consumidor antes do consumo (MONROE \& KRISHMAN, 1985 apud AHMED et al., 2004), podendo ser extrínsecas ou intrínsecas. Produtos podem ser concebidos como sendo um conjunto de pistas de informações intrínsecas e extrínsecas. Exemplos de pistas intrínsecas são gosto, design e textura (INSCH, 2003), e de pistas extrínsecas são COO, marca, preço, garantias, país de design, país de manufatura (LIEFELD, 1993). Quando não existem informações intrínsecas ou estas não podem ser acessadas, o consumidor tende a se basear em informações extrínsecas (ZeITHAML, 1988; INSCH, 2003). Na ausência de elementos suficientes que permitam ao consumidor avaliar um determinado produto de maneira objetiva, o país de origem do produto servirá como substituto ao conhecimento ausente sobre o mesmo (Chéron \& Propeck, 1997). Aspectos intrínsecos são específicos do produto e não podem ser generalizados como indicadores de qualidade em torno de outros produtos. No entanto, pistas extrínsecas como COO podem ser generalizadas para outros artigos produzidos de um país (ZeithamL, 1988).

\section{Efeitos do COO}

Ahmed et al. (2004) destacaram que, segundo Hong \& Wyer (1989), quando a informação do COO é apresentada ao consumidor em conjunto com outras informações, como preço e marca, os efeitos do COO influenciam o eventual comprador de duas maneiras: a partir do efeito "halo" ou a partir de um construto mental. Quando o consumidor não tem familiaridade com produtos de um determinado país, sua imagem deste país serve como um efeito "halo", que influencia de maneira indireta a percepção que ele terá dos produtos daquela nação. No entanto, quando o consumidor tem familiaridade com produtos do país, ele cria um construto mental que indiretamente irá influenciar suas atitudes.

\subsection{Diferentes preocupações dos estudos sobre o efeito $\mathrm{COO}$}

\section{Tipologia de análise do efeito do COO}

Dada a complexidade do tema, alguns autores procuraram classificar os estudos sobre COO segundo 
diversos critérios, existindo algumas revisões da literatura sobre o assunto. Obermiller \& Spangenberg (1989) resumiram de maneira interessante os estudos sobre COO e propuseram uma tipologia de análise que distingue o processamento da percepção de COO em cognitivo, afetivo e normativo. Verlegh \& Steenkamp (1999) retomaram esta classificação dentro de sua metanálise dos estudos sobre COO. Na Tabela 1, a seguir, os autores dão exemplos de cada tipo de estudo.

\section{Cognitivo}

O aspecto cognitivo é o mais presente nos diversos estudos, onde se discute a imagem do produto de um país, que é uma representação mental dos símbolos das pessoas, dos produtos e das culturas deste país (GER, 1991, AskergaARd \& Ger, 1996, 1998, apud Verlegh \& Steenkamp, 1999).

Esta imagem pode variar de produto para produto em um único país. Por exemplo, Leclerc, Schmitt \& Dubé (1994) notaram uma avaliação positiva de produtos franceses quando se trata de perfumes e vinhos, mas uma avaliação negativa de produtos do mesmo país quando se fala de outros artigos produzidos, como carros e computadores.

\section{Afetivo}

Segundo Verlegh \& Steenkamp (1999), muitas vezes certos países têm fortes conotações emocionais associadas para o consumidor, que podem ser formadas por experiências pessoais. Klein, Ettenson
\& Morris (1998) citaram que o fator animosidade pode fazer, por exemplo, com que os chineses tenham uma tendência negativa em relação ao produto japonês em razão de suas guerras e da ocupação japonesa no passado. Obermiller \& Spangenberg (1989) citaram como, também como exemplo, o caso dos estadunidenses de origem árabe que, apesar de reconhecerem a superioridade dos instrumentos óticos israelenses, revelam uma atitude negativa diante dos produtos de Israel. Aspectos como orgulho de usar produtos de uma nação ou relações com o estilo de um país foram ainda citados por Verlegh \& Steenkamp (1999).

\section{Normativo}

Verlegh \& Steenkamp (1999) explicaram que consumidores podem entender que comprar os produtos de um país significa estar dando apoio à sua economia. Não comprar pode significar votar contra políticas daquele país. Por exemplo, pessoas que não compram produtos dos Estados Unidos porque são contrárias à atuação deste país no Iraque. Ahmed et al. (2004) destacaram que os aspectos etnocentristas podem influenciar o consumidor quando este detém a informação do COO. Segundo Shimp \& Sharman (1987), o etnocentrismo determina a opinião do consumidor sobre a pertinência e a moralidade de comprar um produto de um determinado COO. Alguns destes estudos constataram também comportamentos nacionalistas na opinião dos respondentes com relação a produtos fabricados pelo seu próprio país (Chéron \& PROPECK, 1997). Klein, Ettenson \& Morris (1998) mostraram que animosi-

Tabela 1: Classificação dos estudos de COO

\begin{tabular}{ccc}
\hline Mecanismo & Descrição & Principais conclusões \\
\hline Cognitivo & COO é um indicativo para a qualidade do produto. & $\begin{array}{c}\text { O país de origem é usado como um sinal } \\
\text { genérico da qualidade do produto } \\
\text { e de sua durabilidade. }\end{array}$ \\
\hline Afetivo & $\begin{array}{c}\text { O país de origem tem valor emocional e } \\
\text { simbólico para o consumidor. }\end{array}$ & $\begin{array}{c}\text { O país de origem é uma imagem que liga } \\
\text { o produto a beneficios simbólicos } \\
\text { e emocionais, inclusive status social } \\
\text { e orgulho nacional. }\end{array}$ \\
\hline Normativo & $\begin{array}{c}\text { O compra de um produto pode ser vista } \\
\text { como "conduta correta", pois apoia a } \\
\text { pessoais relacionadas no país de origem. }\end{array}$ & $\begin{array}{c}\text { economia doméstica. Ou, da mesma maneira, } \\
\text { os consumidores podem boicotar produtos } \\
\text { por discordarem de aspectos específicos } \\
\text { do país produtor. }\end{array}$ \\
\hline
\end{tabular}

Fonte: adaptado de Verlegh \& Steenkamp., 1999. 
dades contra uma nação também irão influenciar negativamente o comportamento do consumidor. Han (1988) mostrou que consumidores patrióticos têm tendências negativas em relação à compra de produtos estrangeiros.

Outros autores procuraram propor tipologias distintas para o estudo da influência do país de origem nos hábitos de consumo. Roth \& Romeo (1992) formularam um referencial teórico, buscando tecer uma relação entre a preferência do consumidor por produtos de um país e a percepção da cultura, do perfil político e da economia daquele país. Segundo os autores, os consumidores têm uma preferência sobre produtos de uma determinada nação quando entendem que existe uma competência do país para fabricar algum produto em especial.

\section{Diferenças culturais quanto ao COO}

Um tipo de estudo bastante explorado na literatura é a percepção de diferentes consumidores quanto ao país de origem. Nagashima (1970) explorou a diferença de percepção de COO de estadunidenses e de japonses.

O autor publicou os resultados de dois estudos, comparando as atitudes de executivos estadunidenses às de executivos japoneses com relação a produtos fabricados (país de origem) nos Estados Unidos, no Japão, na Inglaterra, na Alemanha, na França e na Itália. O mesmo autor retomou sua análise oito anos mais tarde, a fim de identificar mudanças na percepção do "país de origem" destas diferentes nações (NAGASHIMA, 1977). A partir de uma perspectiva longitudinal, foram efetuadas três pesquisas com amostras aproximadamente iguais nos Estados Unidos e no Japão, entre 1977 e 1992, com o objetivo de identificar a evolução da imagem dos produtos norteamericanos e japoneses no período (Kamins \& NAGASHIMA, 1995). Kamins \& Nagashima (1995) constataram, então, o declínio progressivo da imagem dos produtos originários dos Estados Unidos e a melhora da imagem dos produtos oriundos do Japão.

Além disso, outros autores exploraram os efeitos do país de origem na avaliação de consumidores de países em desenvolvimento. Bandyopadyan (2001) estudou a opinião de consumidores indianos, com relação a produtos fabricados na Índia, nos Estados Unidos, no Japão, na Alemanha, na Grã-Bretanha e na Coreia do Sul. Foi considerada a opinião dos respondentes em termos de qualidade e imagem dos produtos, intensidade de propaganda, imagem e disponibilidade de produtos. Constatou-se uma percepção de que produtos oriundos de países desenvolvidos são considerados superiores em relação aos produtos de países em desenvolvimento. Os produtos indianos, de origem dos respondentes, foram considerados inferiores aos produtos de outros países em termos de qualidade e de imagem. No entanto, os indianos consideram que os produtos originários de seu país possuem uma melhor relação qualidade/ preço que os produtos da Alemanha, dos Estados Unidos e da Grã-Bretanha.

Agbonifoh \& Elimimian (1999) obtiveram resultados comparáveis no tocante à opinião dos consumidores nigerianos em relação aos produtos fabricados na Nigéria, em Gana, no Japão, em Taiwan, na Grã-Bretanha e nos Estados Unidos. Os produtos da Nigéria e de Gana são considerados, pelos nigerianos, inferiores aos produtos oriundos de países industrializados. Os autores exploraram a percepção dos consumidores no que diz respeito à durabilidade dos produtos, ao fato de os produtos estarem na moda, ao valor em termos de relação qualidade/preço, à confiabilidade e à funcionalidade. Contrariamente à opinião dos indianos com relação aos produtos de seu país, os nigerianos consideram seus próprios produtos como tendo um valor inferior aos produzidos nos países desenvolvidos.

Shahid (1997), tendo feito um estudo sobre a opinião dos sauditas em relação aos efeitos do país de origem, constatou que os consumidores saudi-arábicos percebem os produtos do Japão como sendo superiores, seguidos dos produtos estadunidenses e pelos produtos alemães, estes em terceira posição. Os produtos fabricados na Arábia Saudita são colocados na mesma posição que os produtos da Itália, da França e da Grã-Bretanha em termos daquilo que o autor chamou de "atributos centrais do produto".

\section{Consumidores e compradores industriais}

Alguns estudos levantaram a hipótese da existência de um comportamento distinto entre consumidores finais e compradores industriais (CHASSIN \& JAFFE, 1979; INSCH, 2003). Contudo, os compradores industriais não são mais racionais que os consumidores (Huber \& McCanN, 1982; WILSON, 2000, apud INSCH, 2003). Insch (2003) concluiu, apenas parcialmente, 
que há existência de influência tanto do país de design quanto do país de produção de um produto no comportamento do comprador industrial.

\section{Variações demográficas de influência do COO na percepção do consumidor}

Foi constatado que aspectos demográficos têm um papel importante na imagem do COO (SCHOOLER, 1971 apud BALABANIs et al., 2002). Alguns autores exploraram a diferença de influência do COO em termos de sexo e idade, entre outras variáveis demográficas, na percepção dos consumidores. O grau de instrução foi também identificado como fator-chave influente no efeito do "país de origem" (Al-Sulaiti \& BAKER, 1998; FesterVAnd et al., 1985 apud PAsWAN \& Sharma, 2004). Na medida em que aumenta o grau de instrução, aumenta o conhecimento do indivíduo sobre outras culturas e sua tolerância sobre diferenças entre países (PASWAN \& SHARMA, 2004). A variável "classe socioeconômica" também foi considerada um fator influente na confiança que o consumidor tem com relação a produtos estrangeiros (INGLEHART \& BAKER, 2000 apud PASWAN \& Sharma, 2004). Paswan (2004) exploraram aspectos do perfil humano em relação ao COO, avaliando, por exemplo, a relação entre comportamento individualista ou coletivista e a percepção dos consumidores a respeito dos produtos de um país, confirmando parcialemente suas hipóteses, ao constatar que havia diferenças entre a visão do consumidor de um país para outro. GürhanCanli \& Maheswaran (2000a) observaram diferenças significativas no efeito $\mathrm{COO}$ em diferentes culturas, também levando em conta aspectos individualistas ou coletivistas dos consumidores de um país.

\section{Influência do COO para tipos de produto}

Alguns estudos mostraram a preocupação em avaliar a influência do $\mathrm{COO}$ em determinados produtos. A percepção do consumidor e a influência do COO mudaria de acordo com o produto em questão (LECLERC, SCHMITT \& Dubé, 1994). Outros estudos abordaram a influência do COO em relação a produtos específicos, como carne (Brester et al., 2004), café ou pão (AHmed et al., 2004), além da influência do COO na compra de produtos chamados de baixo envolvimento, como artigos perecíveis, de consumo diário, de alto envolvimento (AHMED et al., 2004), transporte (ref.), turismo (AHMED et al., 2002), indústrias ou serviços ainda pouco explorados neste segundo caso (ref.).

\section{País de design (COD) e país de produção (COA)}

Com a globalização das indústrias, tornou-se difícil definir o país de origem de um produto. Muitos produtos são construidos a partir de partes fabricadas em diversas regiões do mundo, o que torna difícil ao consumidor identificar o país de origem do produto final. A preocupação passou a ser a percepção do consumidor quanto a produtos que têm uma marca originaria de um país, mas não necessariamente é fabricado naquele lugar. A Sony e a Toyota são marcas japonesas; no entanto, o carro não é fabricado necessariamente no Japão (ref.). É fabricado no Brasil, por exemplo. Como avaliar, então, a influência do COO? Inch (2003) observou que, na medida em que as pesquisas sobre o tema evoluíram, os pesquisadores começaram a decompor os estudos em aspectos mais específicos como país de design (COD - contry of design) e país de produção (COA country of assembly). Chao (1993) e Ahmed \& d'Astour (1996, apud INSCH, 2003) destacaram o interesse avaliar subdimensões do aspecto COO. Tse \& Lee (1993) constataram uma influência significativa da compostição das partes do produto, tanto em atributos de "longo prazo" quanto na "avaliação geral", o que foi feito por alguns autores (BRODOWSKY \& TAN, 1999; BRODOWSKI, 1998).

\section{Influência de variáveis sociais, políticas e econômicas}

Alguns estudos têm explorado a percepção que o consumidor tem dos produtos de um país como resultado da imagem que ele faz deste país. Neste caso, Passwan \& Sharma (2004) medem a influência da relação entre de variáveis, como situação política do país de origem do produto, sua situação econômica ou, mesmo, seu grau de desenvolvimento e a imagem que o consumidor tem dos produtos de um determinado país. Insh (2003), constatou que o consumidor percebe produtos oriundos de nações desenvolvidas como sendo de melhor qualidade do que produtos originários de países em desenvolvimento.

\section{Influência da imagem do produto na imagem do país}

Se, normalmente, os estudos se preocupam com a influência do país de origem na imagem dos pro- 
dutos deste país, algumas pesquisas revelam uma preocupação contrária, como é o caso do estudo de Gürhan-Canli \& Maheswaran (2000b). Os referidos autores exploraram a influência da informacão do produto nas percepções a respeito do país de origem, isto é, a influência que a imagem que o consumidor tem sobre os produtos de um país gera na imagem que ele tem do país de origem.

\section{Vieses dos estudos de país de origem}

Ayrosa (2000) destacou a existência de certos vieses nas pesquisas sobre "país de origem". O autor destacou que os países desenvolvidos são percebidos como melhores que os países menos desenvolvidos. Destacou, também, que um número muito pequeno de países é usado nestes estudos, ressaltando Japão, Alemanha e EUA como aqueles que têm imagem mais favorável. México, Tailândia e Taiwan são os países considerados como possuidores de imagem desfavorável.

\subsection{Escalas, representações e modelos de medição da influência do COO}

A maneira de medir e avaliar o impacto do COO na percepção do consumidor é uma questão importante na literatura. Não existe uma teoria fundamentada por trás dos estudos de $\mathrm{COO}$ e, segundo Gürhan-Canli \& Maheswaran (2000b), existem muito poucos trabalhos sistemáticos baseados em teorias.

Os primeiros estudos de Nagashima $(1970,1977)$ propuseram uma escala de medidas que se tornou bastante difundida nas pesquisas sobre COO. Por intermédio da escala de Nagashima, busca-se avaliar a imagem dos produtos fabricados pelos países a partir de um conjunto de escalas de Likert de 7 pontos, constituídas por adjetivos bipolares. As escalas propostas, em número de 20, foram agrupados por Nagashima (1970, 1977) em cinco dimensões subjacentes: 1. preço e valor do produto; 2 . natureza dos serviços e engenharia; 3. publicidade e notoriedade; 4. design e estilo; 5. perfil do consumidor. Nagashima $(1970,1977)$ não apresentou um critério explícito para reunir as escalas nas cinco dimensões que propôs.

Outros estudos posteriores procuraram fazê-lo a partir da aplicação de análise fatorial. Han \& Terpstra (1988) evidenciaram quatro dimensões subjacentes: 1. grau de etnicidade; 2. prestígio; 3. qualidade de fabricação; e 4. preço. O estudo não detalhou, no entanto, as escalas ou questões apresentadas aos respondentes. Do mesmo modo, Roth \& Romeo (1992) identificaram quatro dimensões: 1. grau de inovação; 2. design; 3. prestígio; e 4. qualidade de fabricação. Apesar de terem também realizado uma análise fatorial, não apresentam as escalas utilizadas inicialmente nas questões apresentadas aos respondentes.

Heslop \& Papadopoulos (1993, apud Chéron \& Propeck, 1997) determinaram, a partir de uma análise fatorial, três fatores que reagrupam 13 escalas: 1 . integridade do produto; 2 . preço e valor; 3 . presença no mercado.

Chéron \& Propeck (1997) propuseram, finalmente, um modelo com quatro dimensões: 1 . avanço tecnológico; 2. design; 3. prestígio; 4. fabricação. Os autores em tela manifestaram o interesse em realizar uma análise fatorial, a fim de validar sua proposta, mas não o fizeram em seu estudo. A validade do modelo proposto pelos autores ficou, portanto, em suspenso.

Os mesmos Chéron \& Propeck (1997) expuseram o interesse no desenvolvimento de modelos estruturais que permitissem compreender a imagem que se tem de um país, o que faria parte dos fatores que explicam a percepção do consumidor com relação aos produtos daquele país. A hipótese é que a percepção do "país de origem" é função de fatores que determinam a visão do consumidor com respeito àquele país. Em contribuição a este raciocínio, Martin \& Eroglu (1993) exploraram um modelo para a medição da imagempaís, que é baseado em três dimensões, compostas de 14 escalas: 1 . dimensão política; 2 . dimensão econômica; e 3. dimensão tecnológica. Chéron \& Propeck (1997) sugeriram, então, um modelo estrutural que relaciona as seguintes dimensões: 1 . imagem do país; 2. qualidade do produto; 3. ambiente comercial; 4. condições da compra, em um primeiro nível; 5. valor percebido, em um segundo nível, em seguida; e, finalmente, 6. intenção de compra (ver Esquema 1).

Roth \& Romeo (1992) classificaram oito estudos sobre $\mathrm{COO}$ que usaram escalas agrupadas, seja por média dos escores, seja por análise fatorial. Quatro dimensões são comuns a todos estes estudos: inovação, design, prestígio e mão de obra.

Nebenzahl, Jaffe \& Usunier (2003) analisaram 34 pesquisas sobre "país de origem" e constataram uma grande 
Esquema 1: Modelo estrutural adaptado de Chéron \& Propeck (1997)

Imagem do país + qualidade do produto + ambiente comercial + condições de compra $\rightarrow$ valor percebido; valor

percebido + condições de compra $\rightarrow$ intenção de compra

Fonte: adaptado de Chéron \& Propeck (1997).

incidência no uso de escalas que foram "emprestadas" de outros estudos, e que tiveram, segundo os autores, origem na lista de Nagashima (1970), tendo sido modificadas pelos pesquisadores que se seguiram.

Da grande quantidade de estudos existentes sobre COO, a maioria deles buscou captar principalmente três tipos de avaliação do produto: qualidade percebida, atitude e intenção de compra (VERLEGH \& SteEnKAmp, 1999).

\subsection{Limitações dos estudos}

Apesar do grande número de estudos sobre COO, os determinantes das avaliações de COO ainda não são bem entendidas (GÜrHAN-Canli \& MahesWARAN, 2000b). Peterson \& Jolibert (1995: 884) consideraram que os estudos a respeito da influência do COO sobre o consumidor na hora da compra não são conclusivos: "(...) uma questão fundamental permanece. O quão generalizável é o efeito do COO?". Algumas pesquisas mostraram que o peso dado a países de origem não é passível de generalização (Bozzel-Galluo, 1996, BozzelGalluo, 1996; Klein, Ettenson \& MorRIS, 1998 in apud Gürhan-Canli \& Maheswaran, 2000a, Gürhan-Canli \& MAHESWARAN, 2000a), ao comparar diferentes estudos, notou que Maheswaran (1994) mostrou que produtos japonses encontram recepção favorável por parte dos consumidores em geral. No entanto, Klein, Ettenson \& Morris (1998) observaram que os chineses de Nanjung, onde os japoneses foram responsáveis por grandes atrocidades durante a época de ocupação da China, possivelmente não comprariam produtos nipônicos, em razão de sua animosidade em relação ao Japão.

Olsen \& Olsson (2002) entenderam que outras pesquisas deveriam explorar quais características de estudos ou fatores metodológicos influenciam a variável dependente investigada.

Alguns autores ultimamente têm discutido se, ao comprar o produto, o consumidor está realmente preocupado em buscar o COO como informação para sua decisão. Liefeld (2004), em seu trabalho, perguntou a 1.248 consumidores, na saída do caixa, se conheciam o país de origem dos produtos que estavam comprando. O referido pesquisador constatou que $93 \%$ dos consumidores da amostra não sabiam o país de origem do produto que compraram. Dos 91 compradores (6,5\% do total) que conheciam o país de origem do artigo adquirido, apenas 27 (2,2\% do total) afirmaram que tal conhecimento poderia ter exercido influência na hora da compra. O autor mencionado afirmou que muito ainda se deve explorar para conhecer a influência que o COO tem sobre o consumidor na formação de sua imagem do produto.

\section{METODOLOGIA}

\subsection{Escala de medida}

A presente pesquisa baseou-se na escala desenvolvida por Nagashima (1970), uma vez que ela explora uma série de características bipolares que podem ser reagrupadas em dimensões que tendem a expressar a opinião do consumidor. Trabalhar com um número expressivo de critérios de avaliação permite melhor interpretar as avaliações feitas pelos respondentes e identificar perfis coerentes. Além disto, a análise de Nagashima tem o mérito de acrescentar aos atributos do produto aspectos que definem o perfil do consumidor e suas características sociodemográficas, permitindo tirar conclusões com respeito a segmentos de mercado do produto.

Com o objetivo de fazer comparações longitudinais, utilizou-se o questionário empregado durante vários anos por Nagashima. No entanto, não será possível fazer comparações temporais para a percepção do Brasil como país de origem de produtos, uma vez que ele não aparece na lista de países avaliados por este pesquisador. Todavia, o questionário aplicado a duas amostras distintas - executivos de empresas na França e no Brasil, em São Paulo permite realizar uma comparação intercultural. 
Diferentes estudos sobre COO tiveram o objetivo de avaliar escalas, identificar modelos de relacionamento entre variáveis de um construto, como citado anteriormente. Outros trabalhos buscaram identificar a percepção específica de consumidores de um ou mais países. O presente estudo insere-se nessa categoria. Neste sentido, entende-se que a simplicidade da escala de Nagashima (1970) permite analisar a percepção de um consumidor de um determinado país, segundo diversas variáveis, e entender a imagem que este consumidor faz dos produtos de um país, tal como foi feito em estudos anteriores.

As escalas utilizadas por Nagashima e reproduzidas neste estudo são escalas de Likert de 7 pontos, de +3 a -3. Segundo Nagashima (1970), o público entrevistado deve completar o questionário o mais rápido possível, sendo que as respostas devem corresponder à sua primeira impressão.

A escala de medidas utilizada por Nagashima é baseada no método diferencial semântico, proposto por Osgood e al. (1957). Este método foi utilizado por Nagashima $(1970,1975)$ e Kamis \& Nagashima (1995) em seus estudos de influência do countryof-origin na qualidade percebida dos produtos. Como já observado, Nagashima não justificou as dimensões que propôs, o que foi feito por outros estudos por meio de análise fatorial, conforme visto no início do texto.

China e Brasil foram incluídos na lista dos seis países considerados nesta pesquisa, o que permitirá verificar se os países emergentes levam uma desvantagem na avaliação de seus produtos em relação à avaliação dos produtos de países desenvolvidos. Como já mencionado anteriormente, poucos estudos foram realizados procurando identificar a percepção de consumidores de países desenvolvidos com relação a produtos de países em desenvolvimento, tais como o Brasil e a China.

\subsection{Constituição da amostra}

Dois tipos de universo foram pesquisados em duas etapas, a seguir explicitadas.

\section{Etapa 1: estudo da percepção a partir das escalas propostas por Nagashima}

O questionário baseado em 20 escalas propostas por Nagashima (1970) foi respondido por 104 estudantes, pertencentes a cursos de pós-graduação em Administração de Empresas na região de RhonesAlpes, na França, e, em seguida, por 84 estudantes de cursos de Administração, em São Paulo. O referido questionário foi apresentado aos alunos em sala de aula, que responderam a ele presencialmente.

O uso de amostras de conveniência e de estudantes universitários para este tipo de estudo foi observado em outras pesquisas bastante referenciadas na literatura (Roth \& Romeo, 1992; Mohamad, Ahmed \& TYEBKHAN, 2000). Segundo Roth \& Romeo (1992: 484), "(...) apesar de este tipo de amostra homogênea ser um fator limitante, permite a comparação através de diferentes grupos". Além disto, o uso de estudantes que apresenta familiaridade com diversos tipos de produtos e países permite, segundo os autores, solicitar diversas associações de produtos e países.

A escala utilizada nesta pesquisa não apresenta novidades, sendo uma escala bastante consagrada. No entanto, propor novas escalas não foi o objetivo deste trabalho, mas sim poder avaliar o COO do público francês e brasileiro em relação a diversos produtos, o que ainda não havia sido feito.

\section{Etapa 2: percepção geral do francês quanto ao "made in Brazil"}

A fim de completar a análise comparativa do "made in Brazil", foi apresentada a dois grupos de respondentes franceses a seguinte questão: "Quando você pensa no "made in Brazil" quais são os produtos ou atividades que lhe surgem à mente de imediato?". O objetivo foi buscar uma avaliação mais geral do país e um conjunto de produtos de referência que justifiquem esta percepção.

O primeiro grupo foi composto por um conjunto de 54 estudantes em formação equivalente ao último ano de graduação na França, os quais, ainda se encontrando em formação inicial, não tinham uma verdadeira experiência profissional além de estágios em empresas. O segundo grupo de respondentes foi constituído de 27 executivos em formação continuada, mais velhos que os do primeiro grupo e com vários anos de experiência em empresa na função de compras. 


\section{APRESENTAÇÃO DOS RESULTADOS DA ETAPA 1}

\subsection{Análise fatorial}

As dimensões obtidas no presente estudo mostram uma semelhança em relação às dimensões propostas por Nagashima $(1970,1977)$, bem como com relação às dimensões determinadas por outros autores, com algumas diferenças. A Tabela 1, a seguir, apresenta os resultados da análise fatorial com a rotação Varimax e os fatores colocados em ordem crescente de suas cargas. Cinco fatores foram identificados e representados neste quadro.

Na Tabela 2, é feita uma comparação das dimensões encontradas neste estudo com os estudos de Heslop \& Papadopoulos (1993, apud ChÉron \& PropeCK, 1997) e Nagashima (1970, 1977). Uma vez que outros estudos não apresentaram em detalhe as escalas utilizadas, os dados não puderam ser comparados.

Foram aplicados testes de normalidade para cada uma das variáveis, usando-se o teste de Kolmogorof-
Smirnof. A hipótese nula pode ser aceita, assim como os dados tendo distribuição normal, uma vez que todas as distribuições de todas as variáveis têm valores abaixo do valor crítico, com alfa =0,01.

Nota-se que o estudo aqui apresentado, em relação ao estudo de Nagashima, as dimensões de propaganda e reputação, bem como design, foram integrados em grande parte na dimensão nomeada como "imagem e reputação". A escala "preocupação com aparência vs. preocupação com desempenho" foi classificada na dimensão "qualidade", o que é coerente, uma vez que aparência ou desempenho são elementos que podem estar relacionados a uma maior ou menor preocupação com a qualidade.

A escala "produção inovadora vs. imitativa" também foi classificada, no presente modelo, dentro da dimensão "imagem e reputação", diferentemente do modelo de Nagashima, que relacionou este quesito com "serviço e engenharia". "Preço" foi um fator, ou dimensão, claramente destacado neste estudo, o que não foi o caso da proposta de Naga-

Tabela 1: Matriz dos fatores rotacionados - rotação: Varimax com normalização Kaiser

\begin{tabular}{|c|c|c|c|c|c|}
\hline & \multicolumn{5}{|c|}{ Componente } \\
\hline & 1 & 2 & 3 & 4 & 5 \\
\hline $\begin{array}{l}\text { Variedade de modelos (grande variedade de tamanhos } \\
\text { e modelos - variedade limitada) }\end{array}$ & ,753 & $9,176 \mathrm{E}-02$ & $8,571 \mathrm{E}-02$ & $-1,334 \mathrm{E}-02$ & ,275 \\
\hline Propaganda (muita propaganda - pouca propaganda) & ,676 & 197 & ,408 & $3,913 \mathrm{E}-02$ & 164 \\
\hline Produção (inovadora - imitativa) & 651 &, 426 & 324 & $2,753 \mathrm{E}-02$ & $9,786 \mathrm{E}-02$ \\
\hline Marcas (muito conhecidas - desconhecidas) & ,650 & ,260 &, 437 & $6,840 \mathrm{E}-02$ & 155 \\
\hline Orgulho (muito orgulho - pouco orgulho) & ,647 & ,299 & ,298 & $-2,086 \mathrm{E}-02$ & $-7,081 \mathrm{E}-02$ \\
\hline Cores (uso inteligente - uso inadequado) & ,628 & $-7,593 \mathrm{E}-02$ &,- 113 & ,445 &,- 148 \\
\hline Produto (confiável - não confiável) & ,335 & ,742 &,- 124 & $-7,079 \mathrm{E}-02$ & $2,976 \mathrm{E}-02$ \\
\hline Fabricação (cuidadosa - pouco cuidadosa) & ,379 & 697 & ,215 & ,200 & 157 \\
\hline Preocupação (aparência - performance) & ,191 &,- 644 &,- 338 & 177 &,- 115 \\
\hline Artigos (de luxo - de primeira necessidade) &, 519 &, 556 &, 180 & $7,724 \mathrm{E}-02$ & $1,802 \mathrm{E}-02$ \\
\hline Tecnologia (avançada - ultrapassada) & 427 & ,488 & ,259 & ,219 & ,335 \\
\hline Preço (justo - excessivo) &,- 225 & $-4,082 \mathrm{E}-02$ &,- 842 & $3,361 \mathrm{E}-02$ & $3,312 \mathrm{E}-02$ \\
\hline Nível de preço (barato - caro) &,- 342 &,- 269 &,- 768 & $7,304 \mathrm{E}-02$ & $8,213 \mathrm{E}-02$ \\
\hline Voltado para sexo masculino - feminino & $-4,474 \mathrm{E}-02$ & $1,480 \mathrm{E}-03$ & 4,354E-02 & 879 & 100 \\
\hline Destinado a jovens - destinado a idosos & $1,096 \mathrm{E}-02$ & $-8,187 \mathrm{E}-02$ &,- 272 & ,760 & ,116 \\
\hline Destinados a classes de poder aquisitivo (alto - baixo) & ,328 &, 222 & ,363 &, 626 & $-2,985 \mathrm{E}-02$ \\
\hline Produção de massa - artesanal & $6,812 \mathrm{E}-02$ & $5,829 \mathrm{E}-02$ & $-7,779 \mathrm{E}-03$ & 7,413E-03 & 821 \\
\hline Distribuição (âmbito mundial - doméstica) &, 116 & 119 & $-5,692 \mathrm{E}-02$ & 135 & ,807 \\
\hline
\end{tabular}


Tabela 2: Comparação dos fatores ou dimensões deste estudo com outros autores

\begin{tabular}{|c|c|c|c|c|}
\hline \multirow{2}{*}{$\begin{array}{l}\text { Presente estudo } \\
\text { Dimensões }\end{array}$} & \multirow{2}{*}{$\frac{\text { Nagashima (1970) }}{\text { Dimensões }}$} & \multirow{2}{*}{$\begin{array}{l}\text { Indicadores (adjetivos bipolares) } \\
\text { deste estudo a partir de Nagashima }\end{array}$} & \multicolumn{2}{|c|}{ Helosp \& Papadopoulos (1993) } \\
\hline & & & Dimensões & Indicadores (adjetivos bipolares \\
\hline \multirow{6}{*}{$\begin{array}{l}\text { Imagem e } \\
\text { reputação }\end{array}$} & Design & $\begin{array}{l}\text { Variedade de modelos (grande variedade } \\
\text { de tamanhos e modelos - variedade } \\
\text { limitada) }\end{array}$ & \multirow{4}{*}{$\begin{array}{l}\text { Presença de } \\
\text { mercado }\end{array}$} & $\begin{array}{l}\text { Variedade de modelos (grande variedade } \\
\text { de tamanhos e modelos - variedade } \\
\text { limitada) }\end{array}$ \\
\hline & $\begin{array}{l}\text { Propaganda e } \\
\text { reputação }\end{array}$ & Propaganda (muita - pouca) & & Propaganda (muita - pouca) \\
\hline & Serviço e engenharia & Produção (inovadora -imitativa) & & \\
\hline & $\begin{array}{l}\text { Propaganda } \\
\text { e reputação }\end{array}$ & $\begin{array}{l}\text { Marcas (muito conhecidas - } \\
\text { desconhecidas) }\end{array}$ & & $\begin{array}{l}\text { Marcas (muito conhecidas - } \\
\text { desconhecidas) }\end{array}$ \\
\hline & $\begin{array}{l}\text { Propaganda } \\
\text { e reputação }\end{array}$ & $\begin{array}{l}\text { Orgulho (muito orgulho - } \\
\text { pouco orgulho) }\end{array}$ & \multirow{7}{*}{$\begin{array}{l}\text { Integridade } \\
\text { do produto }\end{array}$} & $\begin{array}{l}\text { Boa qualidade de serviço - baixa } \\
\text { qualidade de serviço }\end{array}$ \\
\hline & Design & Cores (uso inteligente - uso inadequado) & & Qualidade superior -qualidade inferior \\
\hline \multirow{5}{*}{ Qualidade } & Preço e valor & Produto (confiável - não confiável) & & Produto (confiável - não confiável) \\
\hline & Serviço e engenharia & Fabricação (cuidadosa -pouco cuidadosa) & & $\begin{array}{l}\text { Nível intenso de mão de obra - baixa } \\
\text { intensidade de mão de obra }\end{array}$ \\
\hline & Design & Preocupação (aparência - performance) & & Preocupação (aparência - performance) \\
\hline & Preço e valor & Artigos (de luxo - de primeira necessidade) & & Produção (inovadora -imitativa) \\
\hline & Serviço e engenharia & Tecnologia (avançada - ultrapassada) & & Tecnologia (avançada - ultrapassada) \\
\hline \multirow{2}{*}{ Preço } & \multirow[t]{2}{*}{ Preço e valor } & Preço (justo - excessivo) & \multirow[t]{2}{*}{ Preço } & Preço (justo - excessivo) \\
\hline & & Nível de preço (barato - caro) & & Nível de preço (barato - caro) \\
\hline \multirow{3}{*}{$\begin{array}{l}\text { Perfil do } \\
\text { consumidor }\end{array}$} & \multirow{3}{*}{$\begin{array}{l}\text { Perfil do } \\
\text { consumidor }\end{array}$} & \multicolumn{3}{|l|}{ Voltado para sexo masculino - feminino } \\
\hline & & \multicolumn{3}{|l|}{ Destinado a jovens - destinado a idosos } \\
\hline & & \multicolumn{3}{|c|}{ Destinado a classes de poder aquisitivo (alto - baixo) } \\
\hline \multirow{2}{*}{ Serviço } & \multirow{2}{*}{ Serviço e engenharia } & Produção de massa - artesanal & & \\
\hline & & Distribuição (âmbito mundial - doméstica) & & \\
\hline
\end{tabular}

shima, que agrupou "preço e valor" em uma só dimensão. Os itens relacionados com "valor", por Nagashima, foram relacionados à "qualidade" no estudo aqui apresentado.

Neste estudo, uma dimensão de serviço ficou claramente destacada através das escalas "produção em massa vs. artesanal" e "distribuição mundial vs. doméstica". Estas escalas foram agrupadas por Nagashima no fator "serviço e engenharia". Também a dimensão "perfil do consumidor" foi claramente destacada na análise fatorial realizada, o que se mostrou coerente com o trabalho de Nagashima. Outras escalas agrupadas por Nagashima na dimensão "serviço e engenharia" encontram-se agrupadas, no presente estudo, nas dimensões "imagem e reputação", bem como "qualidade".
O estudo de Helosp \& Papadopoulos (1993, apud Chéron \& PropeCK, 1997) também trouxe semelhanças com o estudo aqui apresentado, conforme evidencia a Tabela 2.

\subsection{Análise da percepção dos respondentes, segundo o "país-de-origem"}

Na Tabela 3, são apresentadas as médias obtidas para cada país, segundo as escalas do adjetivos bipolares. Desta forma, é possível identificar a percepção dos países de origem, consoante este conjunto de critérios. Ao lado de cada média, é apresentada uma letra. As médias em uma linha, que têm a mesma letra para os diferentes países, indicam que as médias para estes países não são estatisticamente diferentes. 
Tabela 3: Médias obtidas a partir das respostas de executivos e estudantes franceses

\begin{tabular}{|c|c|c|c|c|c|c|c|}
\hline País & França & Brasil & Itália & China & Alemanha & Japão & $\begin{array}{r}\text { Estados } \\
\text { Unidos }\end{array}$ \\
\hline \multicolumn{8}{|l|}{ Imagem e reputação } \\
\hline $\begin{array}{l}\text { Variedade de modelos (grande variedade de tamanhos } \\
\text { e modelos - variedade limitada) }\end{array}$ & $2,2 \mathrm{~A}$ & $5,3 \mathrm{D}$ & $2,8 \mathrm{~B}$ & $4,2 \mathrm{C}$ & $2,6 \mathrm{AB}$ & $2,6 \mathrm{AB}$ & $2,4 \mathrm{~A}$ \\
\hline Propaganda (muita propaganda - pouca propaganda) & $2,4 \mathrm{~B}$ & $5,7 \mathrm{E}$ & $3,2 \mathrm{D}$ & $5,8 \mathrm{E}$ & $2,8 \mathrm{C}$ & $2,8 \mathrm{C}$ & $1,8 \mathrm{~A}$ \\
\hline Produção (inovadora - imitativa) & $2,3 \mathrm{~A}$ & $5,3 \mathrm{C}$ & $3,8 \mathrm{~B}$ & $6,0 \mathrm{D}$ & $2,4 \mathrm{~A}$ & $2,6 \mathrm{~A}$ & $2,3 \mathrm{~A}$ \\
\hline Marcas (muito conhecidas - desconhecidas) & $2,4 A B$ & $5,7 \mathrm{D}$ & $3,2 \mathrm{C}$ & $5,8 \mathrm{D}$ & $2,8 \mathrm{~B}$ & $2,8 \mathrm{~B}$ & $1,8 \mathrm{~A}$ \\
\hline Orgulho (muito orgulho - pouco orgulho) & $2,2 \mathrm{~A}$ & $5,3 \mathrm{C}$ & $3,8 \mathrm{~B}$ & $5,8 \mathrm{D}$ & $2,5 \mathrm{~A}$ & $3,5 \mathrm{~B}$ & $3,6 \mathrm{~B}$ \\
\hline Cores (uso inteligente - uso inadequado) & $3,3 \mathrm{~A}$ & $4,4 \mathrm{C}$ & $3,4 \mathrm{D}$ & $5,0 \mathrm{C}$ & $4,0 \mathrm{BC}$ & $4,0 \mathrm{BC}$ & $3,8 \mathrm{AB}$ \\
\hline \multicolumn{8}{|l|}{ Qualidade } \\
\hline Produto (confiável - não confiável) & $2,7 \mathrm{~A}$ & $4,3 \mathrm{C}$ & $3,5 B$ & $4,4 \mathrm{C}$ & $2,5 \mathrm{~A}$ & $2,8 \mathrm{~A}$ & $3,2 \mathrm{~B}$ \\
\hline Fabricação (cuidadosa - pouco cuidadosa) & $2,5 \mathrm{~B}$ & $4,8 \mathrm{E}$ & $3,6 \mathrm{D}$ & $5,1 \mathrm{E}$ & $2,1 \mathrm{~A}$ & $2,3 A B$ & $3,2 \mathrm{C}$ \\
\hline Preocupação (aparência - performance) & $4,3 \mathrm{C}$ & $3,6 \mathrm{~B}$ & $3,0 \mathrm{~A}$ & $3,7 \mathrm{~B}$ & $5,8 \mathrm{D}$ & $5,5 \mathrm{D}$ & $4,5 \mathrm{C}$ \\
\hline Artigos (de luxo - de primeira necessidade) & $2,4 \mathrm{~A}$ & $5,1 \mathrm{D}$ & $3,5 \mathrm{C}$ & $5,7 \mathrm{E}$ & $2,8 \mathrm{~B}$ & $3,2 \mathrm{BC}$ & $3,3 \mathrm{C}$ \\
\hline Tecnologia (avançada - ultrapassada) & $2,5 \mathrm{~B}$ & $4,8 \mathrm{D}$ & $3,6 \mathrm{C}$ & $4,5 \mathrm{D}$ & $2,3 \mathrm{~B}$ & $1,9 \mathrm{~A}$ & $2,2 \mathrm{AB}$ \\
\hline \multicolumn{8}{|l|}{ Preço } \\
\hline Preço (justo - excessivo) & $4,7 \mathrm{D}$ & $3,1 \mathrm{~B}$ & $3,9 \mathrm{C}$ & $2,1 \mathrm{~A}$ & $5,0 \mathrm{E}$ & $4,4 \mathrm{DE}$ & $4,8 \mathrm{E}$ \\
\hline Nível de preço (barato - caro) & $5,3 \mathrm{D}$ & $3,1 \mathrm{~B}$ & $4,3 \mathrm{C}$ & $2,0 \mathrm{~A}$ & $5,8 \mathrm{E}$ & $5,1 \mathrm{D}$ & $5,2 \mathrm{D}$ \\
\hline \multicolumn{8}{|l|}{ Perfil do consumidor } \\
\hline Voltado para sexo masculino - feminino & $4,8 \mathrm{~B}$ & $4,8 \mathrm{~B}$ & $4,6 \mathrm{AB}$ & $4,3 \mathrm{AB}$ & $4,1 \mathrm{~A}$ & $4,1 \mathrm{~A}$ & $4,3 \mathrm{AB}$ \\
\hline Destinado a jovens - destinado a idosos & $4,4 \mathrm{~B}$ & $3,9 \mathrm{~A}$ & $3,7 \mathrm{~A}$ & $3,7 \mathrm{~A}$ & $5,0 \mathrm{C}$ & $3,8 \mathrm{~A}$ & $4,1 \mathrm{AB}$ \\
\hline Destinado a classes de poder aquisitivo (alto - baixo) & $3,3 \mathrm{AB}$ & $5,7 \mathrm{D}$ & $4,2 \mathrm{C}$ & $6,1 \mathrm{D}$ & $3,0 \mathrm{~A}$ & $3,7 \mathrm{~B}$ & $3,5 \mathrm{~B}$ \\
\hline \multicolumn{8}{|l|}{ Serviço } \\
\hline Produção de massa - artesanal & $3,2 \mathrm{C}$ & $4,3 \mathrm{D}$ & $3,6 \mathrm{C}$ & $2,2 \mathrm{~A}$ & $2,9 \mathrm{~B}$ & $2,2 \mathrm{~A}$ & $2,3 \mathrm{~A}$ \\
\hline Distribuição (âmbito mundial - doméstica) & $3,0 \mathrm{C}$ & $4,1 \mathrm{E}$ & $3,4 \mathrm{D}$ & $2,0 \mathrm{~A}$ & $2,6 \mathrm{~B}$ & $1,9 \mathrm{~A}$ & $2,1 \mathrm{~A}$ \\
\hline Tipo de indústria (pesada - leve) & $3,8 \mathrm{~B}$ & $4,3 \mathrm{C}$ & $4,2 \mathrm{C}$ & $3,7 \mathrm{~B}$ & $2,8 \mathrm{~A}$ & $3,7 \mathrm{~B}$ & $3,2 \mathrm{~A}$ \\
\hline Tipo de produto (exclusivo - comum) & $2,7 \mathrm{~A}$ & $4,5 \mathrm{D}$ & $3,2 \mathrm{BC}$ & $6,0 \mathrm{E}$ & $3,0 \mathrm{AB}$ & $3,3 \mathrm{BC}$ & $3,5 \mathrm{C}$ \\
\hline
\end{tabular}

As médias foram comparadas com uma ANOVA e teste de Waller-Duncan com nível de significância de 0,0001 .

\section{A imagem $\mathrm{COO}$, segundo os franceses}

A imagem do made in Brazil: os preços são vistos como baratos e justos; são produtos de primeira necessidade, fabricados com tecnologia um pouco ultrapassada e a partir de políticas de imitação. É o país que obtém o escore mais longo em termos de "produção em massa" e "distribuição mundial". Os consumidores não expressaram orgulho de ter um produto brasileiro; o produto brasileiro tem pouca propaganda e as marcas são muito pouco conhecidas. O perfil dos consumidores é jovem e os produtos são destinados preferencialmente às mulheres de nível social abaixo da média. As respostas indicam a percepção de produção de matéria-prima por meio de tecnologia ultrapassada e de maneira periférica; produtos de consumo para pessoas mais jovens e de poucos recursos, destinados essencialmente ao consumo interno.

A imagem do made in China: dos seis países tratados, a China é o país cuja imagem mais se aproxima da do Brasil, mas com percepções mais marcadas em termos de preço (muito barato), de artigos de primeira necessidade, de política de imitação, de grau de orgulho na utilização mais baixo. É o país cujo produto é considerado menos diferenciado, menos exclusivo. A visão do consumidor francês quanto ao produto chinês é consideravelmente próxima ao da visão sobre o produto brasileiro. A 
categoria social consumidora do produto chinês é de natureza tão popular quanto a relativa ao Brasil. As avaliações são vizinhas em termos de tecnologia ultrapassada, de marcas pouco conhecidas e de pouco uso de propaganda. No entanto, a imagem da China se distingue da do Brasil em termos de produção em massa e distribuição mundial, quesito no qual a China obtém escores comparáveis aos dos países industrializados (Estados Unidos, Alemanha e Japão).

Imagem do made in France: produtos caros, mas não excessivamente, confiáveis (tal como os produtos dos Estados Unidos e do Japão). A França se destaca, obtendo a média mais elevada em relação a produtos de luxo. Os escores obtidos em termos de escalas de distribuição mundial/doméstica e produção em massa/produção artesanal situam os produtos franceses em uma posição intermediária tendo, de um lado, Japão, China, Estados Unidos e Alemanha e, do outro lado, a Itália (a França e a Itália são vistas no mesmo nível no que se refere à produção artesanal). A imagem "produto de moda" aparece também na opinião dos consumidores, clientela mais para feminina, de público de poder aquisitivo mais elevado. As marcas francesas aparecem, ao lado das marcas estadunidenses, como as mais conhecidas.

Imagem do made in Italy: como já observado, os produtos italianos se situam em uma posição intermediária entre os outros países industrializados e os dois países emergentes (China e Brasil). Os preços dos produtos italianos são considerados de nível intermediário, entre os preços do grupo formado pelo Brasil e pela China, e os de países industrializados. A preocupação com a aparência e a utilização inteligente das cores (escore comparável ao da França) se destacam na percepção do produto italiano. O setor da moda parece influenciar a percepção global do produto italiano (produtos mais para jovens e de classe média).

Imagem do made in Germany: trata-se dos produtos mais caros entre os sete países, de valor um pouco excessivo, sendo os mais confiáveis, equivalentes aos produtos japoneses. Entre os diferentes países, os produtos alemães, ao lado dos japoneses, são aqueles fabricados de maneira mais meticulosa e os mais preocupados com performance. Os produtos alemães, tanto quanto os franceses, são os que trazem mais orgulho ao detentor deles. São mais voltados a pessoas mais velhas e de bom poder aquisitivo. Depois da França, a média dos produtos alemães é a que mais se aproxima da característica "produto de luxo". Tudo indica que a percepção dos produtos deste país se aproxima dos bens de equipamento de alto padrão (marca Mercedes, por exemplo).

Imagem do made in Japan: produtos menos caros e de preço menos excessivo que os da Alemanha, da França ou dos Estados Unidos; são considerados confiáveis e tendendo ao luxo. É o Japão o país que oferece os produtos mais avançados em termos de tecnologia e que dispõem, tanto quanto a China e os Estados Unidos, da melhor distribuição mundial. Tal qual a Alemanha, os produtos japoneses se diferenciam por uma grande preocupação com o desempenho. Em termos do perfil do consumidor, os produtos japoneses são destinados a pessoas relativamente jovens, mais para o sexo masculino e de certo poder aquisitivo.

Imagem do made in USA: os produtos dos Estados Unidos aparecem tão caros quanto os produtos franceses e japoneses, mas de preço considerado um pouco excessivo. Em relação aos produtos da Alemanha, da França e do Japão, os produtos estadunidenses são percebidos como menos confiáveis, de nível de luxo mediano, no mesmo patamar dos italianos, e de fabricação menos meticulosa. Os produtos dos Estados Unidos são vistos como tendo uma boa distribuição mundial, são muito inovadores e suas marcas apresentam-se, tanto quanto as francesas, como as mais conhecidas.

\section{A imagem COO, segundo os brasileiros}

Pode-se observar que, pela comparação entre as Tabelas 3 e 4, a imagem que os brasileiros fazem dos produtos dos diferentes países é bastante próxima da imagem que têm os franceses, inclusive a imagem que os brasileiros têm de seus próprios produtos.

A imagem do made in Brazil: neste caso, também os brasileiros veem seus produtos como baratos e com preço justo, de produção artesanal. Neste quesito, os produtos italianos também são vistos como bastante artesanais. Seus produtos destinamse mais para jovens, perdendo apenas para a China neste quesito; são considerados como tendo a tecnologia mais ultrapassada entre todos os países e não são avaliados como inovadores; a maioria deles 
Tabela 4: Médias obtidas a partir das respostas de executivos e estudantes brasileiros

\begin{tabular}{|c|c|c|c|c|c|c|c|}
\hline País & França & Brasil & Itália & China & Alemanha & Japão & $\begin{array}{r}\text { Estados } \\
\text { Unidos }\end{array}$ \\
\hline \multicolumn{8}{|l|}{ Imagem e reputação } \\
\hline $\begin{array}{l}\text { Variedade de modelos (grande variedade de tamanhos } \\
\text { e modelos - variedade limitada) }\end{array}$ & $2,8 \mathrm{~B}$ & $4,5 \mathrm{E}$ & $3,1 \mathrm{C}$ & $3,8 \mathrm{D}$ & $2,8 \mathrm{BC}$ & $2,4 \mathrm{~A}$ & $2,2 \mathrm{~A}$ \\
\hline Propaganda (muita propaganda - pouca propaganda) & $3,1 \mathrm{C}$ & $5,0 \mathrm{E}$ & $3,5 \mathrm{D}$ & $5,6 \mathrm{~F}$ & $3,1 \mathrm{C}$ & $2,7 \mathrm{~B}$ & $1,8 \mathrm{~A}$ \\
\hline Produção (inovadora - imitativa) & $2,6 \mathrm{C}$ & $4,9 \mathrm{E}$ & $3,5 \mathrm{D}$ & $5,7 \mathrm{~F}$ & $2,4 \mathrm{BC}$ & $2,3 A B$ & $2,1 \mathrm{~A}$ \\
\hline Marcas (muito conhecidas - desconhecidas) & $2,5 \mathrm{C}$ & $5,4 \mathrm{E}$ & $3,1 \mathrm{D}$ & $6,1 \mathrm{~F}$ & $2,5 \mathrm{C}$ & $2,1 \mathrm{~B}$ & $1,7 \mathrm{~A}$ \\
\hline Orgulho (muito orgulho - pouco orgulho) & $2,3 \mathrm{~A}$ & $4,5 \mathrm{D}$ & $3,1 \mathrm{C}$ & $4,8 \mathrm{E}$ & $2,3 \mathrm{~A}$ & $2,8 \mathrm{~B}$ & $3,1 \mathrm{BC}$ \\
\hline Cores (uso inteligente - uso inadequado) & $3,0 \mathrm{~A}$ & $3,9 \mathrm{D}$ & $3,0 \mathrm{AB}$ & $5,1 \mathrm{E}$ & $3,7 \mathrm{D}$ & $3,6 C D$ & $3,3 B C$ \\
\hline \multicolumn{8}{|l|}{ Qualidade } \\
\hline Produto (confiável - não confiável) & $2,8 \mathrm{BC}$ & $4,1 E$ & $3,3 \mathrm{D}$ & $4,6 \mathrm{~F}$ & $2,4 \mathrm{~A}$ & $2,5 \mathrm{AB}$ & $2,8 \mathrm{C}$ \\
\hline Fabricação (cuidadosa - pouco cuidadosa) & $2,5 \mathrm{~B}$ & $4,6 \mathrm{~B}$ & $3,6 \mathrm{D}$ & $5,3 \mathrm{~F}$ & $2,0 \mathrm{~A}$ & $2,1 \mathrm{~A}$ & $2,8 \mathrm{C}$ \\
\hline Preocupação (aparência - performance) & $3,5 B$ & $3,7 B C$ & $2,9 \mathrm{~A}$ & $3,9 \mathrm{C}$ & $5,4 \mathrm{E}$ & $5,2 \mathrm{E}$ & $4,3 \mathrm{D}$ \\
\hline Artigos (de luxo - de primeira necessidade) & $2,2 \mathrm{~A}$ & $5,0 \mathrm{D}$ & $3,1 \mathrm{C}$ & & $2,8 \mathrm{~B}$ & $3,1 \mathrm{C}$ & $3,3 \mathrm{D}$ \\
\hline Tecnologia (avançada - ultrapassada) & $2,4 \mathrm{C}$ & $4,6 \mathrm{E}$ & $3,4 \mathrm{D}$ & $4,4 \mathrm{E}$ & $2,0 \mathrm{~B}$ & $1,6 \mathrm{~A}$ & $1,9 \mathrm{~B}$ \\
\hline \multicolumn{8}{|l|}{ Preço } \\
\hline Preço (justo - excessivo) & $4,9 \mathrm{E}$ & $3,3 \mathrm{~B}$ & $4,2 \mathrm{C}$ & $2,1 \mathrm{~A}$ & $4,8 \mathrm{E}$ & $4,5 \mathrm{D}$ & $4,5 \mathrm{D}$ \\
\hline Nível de preço (barato - caro) & $5,4 \mathrm{EF}$ & $3,2 \mathrm{~B}$ & $4,7 \mathrm{C}$ & $1,9 \mathrm{~A}$ & $5,7 \mathrm{~F}$ & $5,4 \mathrm{E}$ & $5,1 \mathrm{D}$ \\
\hline \multicolumn{8}{|l|}{ Perfil do consumidor } \\
\hline Voltado para sexo masculino - feminino & $5,0 \mathrm{E}$ & $4,3 \mathrm{D}$ & $4,6 \mathrm{D}$ & $3,9 B C$ & $3,5 \mathrm{~A}$ & $3,7 \mathrm{AB}$ & $4,0 C D$ \\
\hline Destinado a jovens - destinado a idosos & $4,7 \mathrm{D}$ & $3,6 \mathrm{~B}$ & $4,1 \mathrm{C}$ & $3,3 \mathrm{~A}$ & $5,0 D$ & $3,7 \mathrm{~B}$ & $3,7 \mathrm{~B}$ \\
\hline Destinado a classes de poder aquisitivo (alto - baixo) & $2,7 \mathrm{~A}$ & $5,2 \mathrm{C}$ & $3,4 \mathrm{~B}$ & $6,1 \mathrm{D}$ & $2,7 \mathrm{~A}$ & $3,2 \mathrm{~B}$ & $3,2 \mathrm{~B}$ \\
\hline \multicolumn{8}{|l|}{ Serviço } \\
\hline Produção de massa - artesanal & $3,5 \mathrm{D}$ & $3,8 \mathrm{E}$ & $3,7 \mathrm{DE}$ & $2,0 \mathrm{~A}$ & $2,8 \mathrm{C}$ & $2,2 A B$ & $2,3 \mathrm{~B}$ \\
\hline Distribuição (âmbito mundial - doméstica) & $3,0 \mathrm{C}$ & $4,3 \mathrm{E}$ & $3,4 \mathrm{D}$ & $1,7 \mathrm{~A}$ & $2,6 \mathrm{~B}$ & $1,7 \mathrm{~A}$ & $2,0 \mathrm{~A}$ \\
\hline Tipo de indústria (pesada - leve) & $4,4 \mathrm{D}$ & $4,1 \mathrm{C}$ & $4,5 \mathrm{D}$ & $4,2 \mathrm{D}$ & $2,7 \mathrm{~A}$ & $3,8 \mathrm{C}$ & $3,4 \mathrm{~B}$ \\
\hline Tipo de produto (exclusivo - comum) & $4,4 \mathrm{D}$ & $4,1 \mathrm{C}$ & $4,5 \mathrm{D}$ & $4,4 \mathrm{D}$ & $2,7 \mathrm{~A}$ & $3,8 \mathrm{C}$ & $3,4 \mathrm{~B}$ \\
\hline
\end{tabular}

tem marcas desconhecidas e são artigos de primeira necessidade.

A imagem do made in France: outra vez a imagem do produto francês, para os brasileiros, é bastante semelhante à que os franceses têm de seus próprios produtos. Nota-se, no entanto, que o brasileiro tende a ver os produtos alemães e estadunidenses como mais exclusivos e que têm uma visão de que os produtos franceses tão comuns quanto os brasileiros. $\mathrm{Na}$ Tabela 3, podem ser vistos os valores das médias das opiniões dos dois países confrontadas. Os brasileiros não colocam os produtos franceses entre os mais inovadores (C), considerando os produtos estadunidenses $(A)$ e japoneses $(A B)$ os que mais se enquadram nesta categoria. Já os franceses consideram seus próprios produtos tão inovadores quanto os estadunidenses, alemães e japoneses. Já em termos de confiabilidade de produto, os brasileiros confiam mais nos produtos germânicos e nipônicos, mas consideram os produtos franceses tão confiáveis quanto os produtos americanos.

A imagem do made in China: a imagem que o brasileiro tem dos produtos chineses se assemelha bastante à avaliação efetuada pelos franceses, que é semelhante à imagem dos produtos brasileiros, conforme visto anteriormente.

A imagem do made in Italy: nota-se que o brasileiro tem uma percepção do produto italiano como sendo um pouco mais diferenciado que a percepção do francês, em termos de poder aquisitivo do consumidor e de qualidade.

A imagem do made in USA: decididamente, o brasileiro tem o produto estadunidense como de melhor imagem e reputação. Considera-o acima dos outros em termos de variedade, propaganda e 
conhecimento da marca e inovação. Mas esta opinião não difere muito da dos franceses. As marcas americanas não são as que causam maior orgulho aos brasileiros ao usá-las, sendo este quesito mais voltado para os produtos franceses. Em termos de inovação, os norte-americanos não são considerados tão inovadores, mas sim os japoneses.

A imagem do made in Germany: o produto alemão ganha em exclusividade para os brasileiros (A). Os produtos americanos vêm em segundo lugar (B) e os franceses, em quarto (D), opinião que não é compartilhada pelos respondentes franceses, que consideram seus produtos os mais exclusivos.

A imagem do made in Japan: os quesitos "avanço tecnológico" e "cuidado na fabricação" se destacam na opinião dos brasileiros, que, no entanto, consideram o uso de cores dos produtos deste país bastante inadequados, e são voltados bem mais para a performance do que para a aparência.

Os valores das médias das respostas dos franceses são retomados nos gráficos da Figura 1, representação usada nos estudos de Nagashima (1970, 1977). O gráfico da percepção da opinião dos brasileiros não foi colocado por uma questão de espaço, em razão de ser bastante parecido com o francês.

A partir desta análise, é possível perceber que existe, de maneira geral, uma hierarquia onde se percebem três grupos distintos de produtos-país. Um primeiro grupo é composto pela China e pelo Brasil, bastante próximos; um segundo grupo, isolado, é representado pela Itália; e um terceiro grupo é representado pela França, pela Alemanha, pelo Japão e pelos Estados Unidos. A China recebe a avaliação mais desfavorável em termos de qualidade do produto e capacidade de inovação, mas muito próxima do made in Brazil, que se situa entre a China e a Itália. No caso da Itália, seus produtos têm uma avaliação mediana. O Japão, a Alemanha, a França e os Estados Unidos possuem uma imagem, quanto à tecnologia, bem mais favorável.

\section{APRESENTAÇÃO DOS RESULTADOS DA ETAPA 2: PERCEPÇÃO DO FRANCÊS EM RELAÇÃO AO PRODUTO MADE IN BRAZIL}

Conforme foi dito anteriormente, a fim de completar a análise comparativa do "made in Brazil", foi apresentada aos respondentes franceses a seguinte questão: "Quando você pensa no "made in Brazil", quais são os produtos ou atividades que lhe surgem à mente de imediato?". Como já destacado, o objetivo foi buscar uma avaliação mais geral do País e um conjunto de produtos de referência, que justifiquem esta percepção.

De maneira espontânea, as respostas a esta pergunta podem destacar certos estereótipos, de maneira mais objetiva, a respeito das atividades econômicas brasileiras que são mais conhecidas na França. As diferenças na lembrança de atividades do país, a partir das pessoas consultadas, se baseiam no nível variado de conhecimento que elas demonstram sobre o País. Para ilustrar este ponto, foram abordadas duas amostras diferentes de população.

A primeira foi composta por um conjunto de 54 estudantes em formação equivalente ao último ano de graduação na França, que ainda se encontravam em formação inicial e não possuíam uma verdadeira experiência profissional, além de estágios em empresas. O segundo grupo de respondentes foi constituído por 27 executivos em formação continuada, mais velhos que o primeiro grupo, e com vários anos de experiência em empresas em funções relacionadas à compras. A questão é saber se este segundo grupo, mais bem informado sobre a participação do Brasil no comércio internacional, foi capaz de fornecer respostas mais objetivas e mais coerentes com as características básicas da indústria brasileira.

Esta análise, baseada em duas amostras distintas, teve o objetivo de destacar o impacto da variável "disponibilidade de informação" sobre as respostas obtidas. A "disponibilidade de informação" foi um dos critérios constatados por Peterson \& Jolibert (1995) entre os aspectos que influenciam os efeitos do país de origem. Do mesmo modo, Han \& Terpstra (1988) integraram a variável "disponibilidade de informação" em sua análise sobre o efeito do país de origem na avaliação de seus produtos.

A Tabela 5 indica as respostas obtidas dos estudantes de graduação. Foi proposto aos alunos que citassem até cinco atividades ou produtos. Os dados apresentados neste grupo são as frequências obtidas em cada citação, segundo sua classificação. 


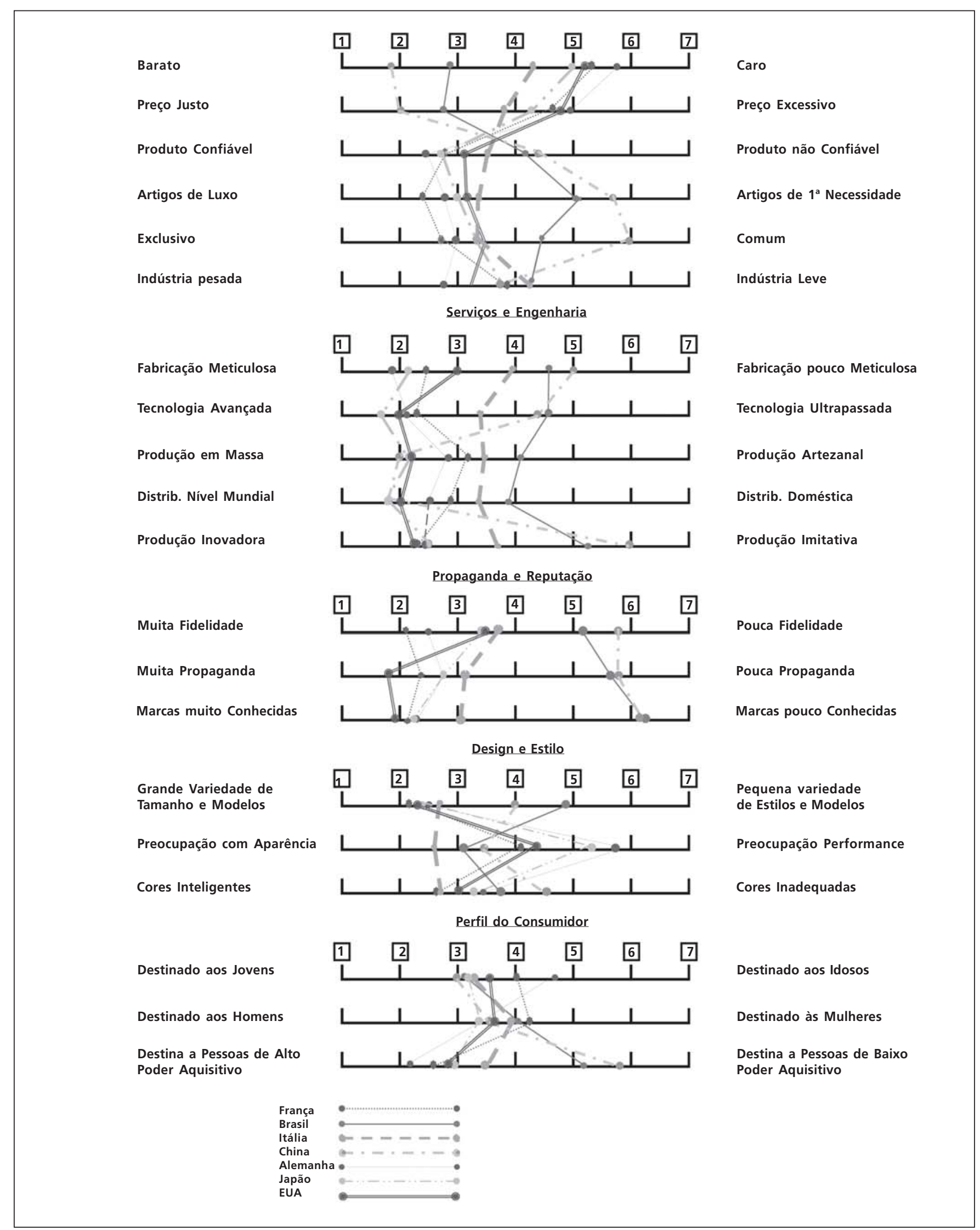

Figura 1: Média das Respostas sobre Opinião dos Produtos 
Tabela 5: Lista dos produtos e serviços associados à imagem do Brasil (amostra de 54 estudantes de graduação)

\begin{tabular}{|c|c|c|c|c|c|}
\hline Ordem de classificação por citação & 1 & 2 & 3 & 4 & 5 \\
\hline \multicolumn{6}{|l|}{ Principais produtos citados } \\
\hline Café & 16 & 10 & 7 & 0 & 0 \\
\hline Carnaval & 12 & 9 & 1 & 4 & 0 \\
\hline Futebol & 11 & 8 & 2 & 5 & 3 \\
\hline Música/dança & 5 & 8 & 7 & 3 & 1 \\
\hline Cirurgia plástica & 3 & 1 & 9 & 0 & 3 \\
\hline Turismo & 2 & 1 & 3 & 2 & 1 \\
\hline \multicolumn{6}{|l|}{ Vestuário } \\
\hline Biquínis & 1 & 2 & 2 & 3 & 1 \\
\hline Roupas & 1 & 1 & 0 & 1 & 1 \\
\hline Couro e calçados & 1 & 1 & 0 & 0 & 0 \\
\hline Maiôs de banho & 0 & 5 & 0 & 1 & 0 \\
\hline Chinelos & 0 & 1 & 1 & 0 & 0 \\
\hline \multicolumn{6}{|l|}{ Agroindústria } \\
\hline Frutas & 1 & 1 & 1 & 2 & 1 \\
\hline Cacau & 0 & 1 & 2 & 0 & 0 \\
\hline Carne & 0 & 1 & 2 & 0 & 0 \\
\hline Bebida (álcool de cana) & 0 & 1 & 0 & 0 & 0 \\
\hline Charutos & 0 & 0 & 1 & 1 & 0 \\
\hline \multicolumn{6}{|l|}{ Mídia } \\
\hline Televisão (Rede Globo) & 0 & 0 & 0 & 1 & 0 \\
\hline
\end{tabular}

As quatro dimensões mais frequentemente citadas foram café, carnaval, futebol e música popular brasileira associada à dança (samba, capoeira). Ao lado deste aspecto festivo e futebolístico, a imagem do Brasil associada à preocupação com a aparência física (culto ao corpo) é indicada pela frequência com que foi citada a atividade de cirurgia plástica.

Do ponto de vista industrial, somente dois setores foram mencionados:

- vestuário: com referências associadas à imagem tropical e de lazer: produtos de praia (chinelos, maiôs de banho e biquínis);

- agroindústria: café, frutas, carne e cachaça.

Em resumo, mesmo que estas respostas correspondessem a atividades econômicas realmente existentes no país, é possível considerar estes resultados principalmente ligados a estereótipos desenvolvidos pela mídia e pelas atividades turísticas. Tais estereótipos simplesmente ignoram toda a gama de atividades industriais efetuadas no país.

A Tabela 6 apresenta as respostas obtidas a partir da segunda amostra, composta por executivos.

Tabela 6: Lista dos produtos e atividades associadas à imagem do Brasil (amostra de 27 compradores profissionais)

\begin{tabular}{llllll}
\hline Classificação das citações & $\mathbf{1}$ & $\mathbf{2}$ & $\mathbf{3}$ & $\mathbf{4}$ & $\mathbf{5}$ \\
\hline Café & 8 & 3 & 3 & 2 & 0 \\
\hline Aeronáutica/Embraer & 3 & 1 & 1 & 0 & 0 \\
\hline Vestuário/têxtil & 2 & 2 & 2 & 0 & 0 \\
\hline Veículos/autopeças & 1 & 2 & 2 & 0 & 0 \\
\hline Frutas/sucos de frutas & 1 & 2 & 1 & 0 & 1 \\
\hline Madeira & 1 & 2 & 1 & 0 & 0 \\
\hline Futebol & 1 & 1 & 1 & 0 & 1 \\
\hline Turismo & 1 & 1 & 0 & 1 & 1 \\
\hline Minerais & 1 & 0 & 1 & 0 & 0 \\
\hline Maiôs de banho & 1 & 0 & 0 & 0 & 0 \\
\hline Chinelos & 1 & 0 & 0 & 0 & 0 \\
\hline Vôlei de praia & 0 & 1 & 0 & 0 & 0 \\
\hline Cirurgia plástica & 0 & 0 & 2 & 0 & 0 \\
\hline Borracha & 0 & 0 & 1 & 1 & 0 \\
\hline Álcool de cana/cachaça & 0 & 0 & 1 & 0 & 0 \\
\hline Eletrodomésticos & 0 & 0 & 1 & 0 & 0 \\
\hline Oculos de sol & 0 & 0 & 0 & 1 & 0 \\
\hline Celulose & 0 & 0 & 0 & 1 & 0 \\
\hline Creme solar & 0 & 0 & 0 & 0 & 1 \\
\hline
\end{tabular}

Mesmo encontrando algumas das atividades mais citadas na amostra anterior (café e futebol), algumas não são mais citadas pelos respondentes (música e dança). Por outro lado, as respostas incluem setores não citados precedentemente: indústria aeronáutica, indústria de tecidos, da madeira e celulose, equipamentos de automóvel, indústria mineral, eletrodomésticos. Os setores citados são variados e ilustram para este grupo um melhor conhecimento da economia brasileira. A função de comprador, que é a formação do grupo pesquisado, exige cada vez mais uma visão global, o que provavelmente explica a disparidade de respostas obtidas em cada uma das duas amostras.

Na segunda amostra, se bem que em menor frequência, os produtos ligados à praia também foram 
citados (maiôs de banho, chinelos, óculos de sol, vôlei de praia) e é possivelmente neste setor de atividade que haja mais conotações favoráveis entre a imagem do país e a percepção positiva de produtos. O sucesso das "Havaianas", da Alpargatas, no exterior ilustra este aspecto. Chinelos desta marca são exportados para 140 países. Em 40 anos, a empresa fabricou mais de três milhões de pares, $40 \%$ destinados à exportação, sendo distribuídas nas mais renomadas lojas na Europa e nos Estados Unidos. A Associação Brasileira da Indústria Têxtil deseja promover esta tendência e constatou que o país aparece de maneira crescente como um polo criador de "moda de praia", essencialmente feminina.

\section{CONCLUSÕES}

A preocupação com o tema "efeito do país de origem" surgiu neste artigo a partir de um estudo de mercado efetuado na França para a indústria brasileira de calçados (CAStel \& Drouvot, 2002), trabalho financiado pela Associação Brasileira da Indústria de Calçados e pela Agence de Promotion des Exportations, Apex, que permitiu constatar a impossibilidade de estruturar um questionário destinado a avaliar a percepção dos calçados junto a uma amostra de consumidores franceses.

Como seria possível comparar a produção brasileira à de países concorrentes, se a população francesa ignora que o Brasil é um grande exportador de calçados? É pouco provável que esta situação mude sem ações brasileiras de promoção, haja vista a imagem do consumidor francês em relação aos produtos brasileiros. Este fator é agravado pelo fato de que, atualmente, de forma diferente dos Estados Unidos, na União Europeia não há mais a obrigação de colocar sobre o produto a indicação "país de origem". O grande aumento de importações de calçados da China ou do Vietnã é, desta forma, dissimulado, evitando um excesso de reações nacionalistas. De qualquer maneira, pode-se notar, nesta pesquisa, que os produtos brasileiros não observam vantagem em relação aos produtos chineses, em termos de percepção por parte dos consumidores franceses. Ao contrário, além de formarem uma opinião semelhante em termos de qualidade e imagem dos produtos brasileiros e chineses, consideram os chineses mais baratos.

No mesmo sentido, um artigo da Gazeta Mercantil (2003) sobre as exportações brasileiras de móveis para o mercado norte-americano constatou que o consumidor estadunidense raramente conhece a origem dos produtos, sendo que os móveis brasileiros são exportados, em sua grande maioria, sem marca e sem indicação do país de origem.

Assim, é fundamental promover a imagem industrial do Brasil. A indústria aeronáutica poderia, neste sentido, ser um excelente instrumento de comunicação. Afinal, o sucesso da Embraer, quarto produtor mundial de aviões, deveria ser tema de artigos na mídia internacional.

A preocupação em confrontar a imagem da indústria de um país se manifesta também na Argentina. Para Redrado (2003), um dos desafios das políticas públicas argentinas é justamente trabalhar na criação de uma identidade e uma reputação comum a todos os produtos nacionais, isto é, na criação de uma "marca argentina", permitindo diferenciar-se qualitativamente no âmbito internacional. O autor manifestou consciência de que é necessário a produção se amparar em um engajamento duradouro, integrando-se a outras políticas que favoreçam a competitividade e inovação, o que necessita da colaboração íntima das agências governamentais de promoção de exportação e da indústria preocupada em desenvolver sua presença no mercado internacional. 


\section{REFERÊNCIAS}

Agbonifoh, Barnabas A. \& Elimimian, Jonathan U. Attitudes of developing countries towards "country-of-origin" products in an era of multiple brands. Journal of International Consumer Marketing, vol. 11, n. 4, p. 97-116, 1999.

Ahmed, Zafar U.; Johnson, James P.; Yang, Xia; Fatt, Chen Kheng; Teng, Han Sack \& Boon, Lim Chee. Does country of origin matter for low involvement products? International Marketing Review, 21, 1, p. 102-120, 2004.

Ahmed, Zafar U.; Johnson, James P.; LING, Chew Pei; FANG, Tan Wai. \& Hul, Ang Kah. Country-of-origin and brand effects on consumer's evaluation of cruise lines. International Marketing Review, 19, 2/3, p. 279-302, 2002.

Andersen, Paul Houman \& Chao, Paul. Management International Review, fourth quarter vol. 43, N. 4, P. 339-361, 2003.

Askegatrd, S. \& Ger, G. Product-Country images as stereotypes: A comparative study. Proceedings of the 21 st Annual Colloquium of the I.A.R.E.P. P. 13-28, 1996.

Aurier, Philippe \& Fort, Fatiha. Effets de la région d'origine, du produit, de la marque et de leurs congruences, sur l'évaluation des consommateurs: application aux produits agroalimentaires. Recherche et Applications en Marketing, vol. 20, Iss. 4; p. 29-53, 2005.

Ayrosa, Eduardo André T. Imagem de país: uma escala para avaliar as atitudes relativas a países. In: XXII Encontro Anual da associação Nacional de PósGraduaÇÃo em Administração - EnAnpad, Foz do lguaçu. Anais... Foz do Iguaçu: Anpad, 1998. CD-ROOM.

Balabanis, George; Mueller, Rene \& Melewar, T. C. The Human values' lenses of country of origin images. International Marketing Review, vol. 19, n. 6, p. 582-609, 2002.

BANDYOPADHYAY, Soumava. Competitiveness of foreign products as perceived by consumers in the emerging Indian market. Competitiveness Review, vol. 11, n. 1, p. 53-64, 2001.

Brester, Gary; Marsh, John M. \& Atwood, Joseph A. Distributional impact of country-of-origin labeling in the US meat industry. Journal of Agri- cultural and Resource Economics, August, 21, 2, p. 206-227, 2004.

BrodowskI, Glen H. The effects of country of design and country of assembly on evaluative beliefs and attitudes toward buying them: A comparison between low and high ethnocentric consumers. Journal of International Consumer Marketing, vol. 10, n. 3, p. 85-114, 1998.

BRODOWsKl, Glen H. \& TAN, Justin J. Managing country of origin: Understanding how country of design and country of assembly affect product evaluations and attitudes toward purchase. American Marketing Association. Conference Proceedings, p. 307-320, 1999.

Brozzel-Gallup. The Second Annual Bozell-Gallup Worldwide Poll. New York: Bozell Worldwide, 1996. Castel, F. \& Drouvot, Hubert. Relatório da pesquisa do Mercado na França para a indústria brasileira de calçados. América Consultoria, ABI-Calçados, Apex, Porto Alegre, março, 2002.

CATtin, Philippe; Jolibert, Alain \& Lohnes, Colleen. Crosscultural study of "made in" concepts. Journal of International Business Studies, vol. 14, p. 131-141, 1982.

Chao, Paul; Wuhrer, Gerhard \& Werani, Thomas. Celebrity and foreign brand name as moderators of country-of-origin effects. International Journal of Advertising, 24(2): 173-192, 2005.

ChASSIN, Joseph B. \& JAFFE, Eugene D. Industrial buyer attitude towards goods made in Eastern Europe. Columbia Journal of World Business, vol. 14, p. 7481, 1979.

Chéron, Emmanuel \& Propeck, Jan. The effects of origin on the evaluation of products, a state of the art review and research proposition. IAE de Paris, Université Paris 1, p. 2-20, 1997.

FesterVAnd, T; LUMPKIN, J. \& LUnDSTROM, W. Consumers' perception of imports: an update and extension. Akron Business and Economics Review, vol. 16, p. 31-6, 1985.

GAEDEKE, Ralph. Consumer attitude towards products "made in" developing countries. Journal of Retailing, 49 (2), p. 13-24, 1973.

Gazeta Mercantil. Cresce exportação com design nacional. Clipping de notícias, 18/06/2003. Disponível em: <http://www.ipef.br/servicos/ clipping/view.asp?ld=72>. 


\section{REFERENCIAS}

Ger, G. Country image: Perceptions, attitudes, associations, and their relationships to context. Proceedings of the 3rd International Conference on Marketing and Development, p. 390-398, 1991.

GÜrhan-Canli, Zeynep \& Maheswaran, Durairaj. Cultural variations in country of origin effects. Journal of Marketing Research, August, vol. 37, n. 2, p. 309-317, 2000a.

. Determinants of country-of-origin evaluations. Journal of Consumer Research, June, vol. 27, n. 1, p. 96-108, 2000b.

$\mathrm{H}_{\mathrm{AN}}, \mathrm{C}$. Min. The role of consumer patriotism in the choice of domestic versus foreign products. Journal of Advertising Research, vol. 28, n. 3 (June/ July), p. 25-32, 1988.

Han, C. Min \& Terpstra, Vern. Country-of-origin effects for uni-national and bi-national products. Journal of International Business Studies, vol. 19, n. 3, p. 235-255, 1988.

Heslop, Louise A.; LIefeld, John \& WalL, Marjorie. An experimental study of the impact of $\mathrm{COO}$ information. In: Turner, Ronald E. (ed.). Proceedings of the Annual Conference of the Administrative Science Association of Canada. Toronto: Administrative Sciences Association of Canada, June, 1987. HONG, Sung-Tai, WYeR, Robert S., Jr.. Effects Of Country-Of-Origin And Product-Attribute Informat, Journal of Consumer Research. Sep. vol. 16, n. 2; p. 175-188, 1989.

HUBer, Joel \& McCANn, John. The impact of inferential beliefs on product evaluations. JMR, Journal of Marketing Research. Aug, vol. 19, n. 3; p. 324-334, 1982.

INSCH, Gary S. The impact of country-of-origin effects on industrial buyer's perceptions of product quality. Management International Review, third quarter, vol. 43, n. 3, p. 291-310, 2003.

INSCH, Gary S. \& McBriDE, J. Brad. The impact of country-of-origin cues on consumer perceptions of product quality: A bi-national test of the decomposed country-of-origin construct. Journal of Business Research, 57: p. 256-265, 2004.

Kamins, Michael A. \& Nagashima, Akira. Perceptions of products made in Japan versus made in the United States among Japanese and American execu- tives: A longitudinal perspective. Asia Pacific Journal of Management, vol. 12, n. 1, p. 49-68, 1995.

KAYNAK, Erdener \& KARA, Ali. Consumer perception of foreign products - An analysis of product-country images and ethnocentrism. European Journal of Marketing, vol. 37, n. 7/8, p. 928-949, 2002.

Klein, Jill G.; ETtenson, Richard \& Morris, Marlene D. The animosity model of foreign product purchase: An empirical test in people's Republic of China. Journal of Marketing, vol. 62, 1, p. 89-100, 1998.

KIEN-Quoc, Vam Pham. Strategic offshoring from a decomposed COO's perspective: A cross-regional study of four product categories. Journal of American Academy of Business, vol. 8, Iss. 2; p. 59-67, 2006. Lawrence, C.; Marr, Norman E. \& Prendergast, Gerard P. Country-of-origin stereotyping: A case study in New Zealand motor vehicle industry. European Journal of Marketing, vol. 26, n. 3, p. 37-51, 1992.

LeClerC, France, SChmitt, Bernd H, Dube, Laurette. $J M R$, Journal of Marketing Research, May, vol. 31, n. 2; p. 263-270,1994.

Levy, Luiz Fernando. O novo Brasil. São Paulo: Gazeta Mercantil/Nobel, 2002

LIEFELD, John P. Experiments on country-of-origin effects: Review and meta-analysis of effect size. In: Papadopoulos, Nicolas \& Heslop, Louise A. (eds.). Product country images: impact and role in international marketing. New York: International Business Press, 1993. p. 117-156,

Consumer knowledge and use of countryof-origin information at the point of purchase. Journal of Consumer Behavior, December, vol. 4, n. 2, p. 85-96, 2004.

Lilus, Charles M. \& Naranya, Chem L. Analysis of "made in" product-images - An exploratory study. Journal of International Business Studies, vol. 5, n. 1, p. 119-127, 1974.

LOUReIRO, Maria L. \& Umberger, Wendy J. Estimating consumer willingness to pay for country-of-origin labeling. Journal of Agricultural and Resource Economics, August, 28, 2, p. 287-301, 2003.

Maheswaran, Durairaj. Journal of Consumer Research. vol. 21, n. 2; p. 354 -366, 1994.

Mohamad, Osman; Ahmed, Zafar U., Honeycutt Jr, Earl D. \& TYeBkHAn, Taizoon Hyder, Does "made 


\section{REFERÊNCIAS}

in..." matter to consumers? A Malaysian study of country of origin effect. Multinational Business Review, vol. 8, n.2, Fall, p.69-73, 2000.

NAGASHIMA, Akira. A comparison of Japanese and US attitudes toward foreign products. Journal of Marketing, vol. 34, Janvier, p. 68-74, 1970.

A comparative "made in" product image survey among Japanese businessmen. Journal of Marketing, July, p. 95-100, 1977.

Nebenzahl, Israel D.; Jaffe, Eugene D. \& Usunier, J.C. Personifying Country of Origin Research. Management International Review, fourth quarter, vol. 43, n.4, p.383-406, 2003.

Obermilleer, Carl \& Spangenberg, Eric. Exploring the effects of country-of-origin labels: An information processing framework. Advances in Consumer Research, vol. 16, p. 454-459, 1989.

Olsen, Svein Ottar; OLsSON, UIf H. Journal of International Business Studies. First Quarter, v. 33,

n. 1; p. 149-168, 2002

Osgood, Charles E.; Sucl, George J. \& Tannenbaum, Percy $\mathrm{H}$. The measurement of meaning. Urbana, Illinois: University of Illinois Press, 1957.

Papadopoulos, Nicolas \& Heslop, Louise A. Country equity and country branding: problems and prospects. Journal of Brand Management, April, vol. 9, n. 4-5, p. 294-314, 2002.

Papadopoulos, Nicolas; Heslop, Louise A. \& Bamossy, Gary. A Comparative image analysis of domestic versus imported products. International Journal of Research in Marketing, vol. 7, n. 4, p. 283-94, 1990.

Paswan, Audehsh K. \& Sharma, Dheeraj. Brandcountry of origin ( $\mathrm{COO}$ ) knowledge and $\mathrm{COO}$ image: investigation in a franchose market. The Journal of Product and Brand Management. vol. 13, n.2/3, p.144-155, 2004.

PHARR, Julie M. Synthesizing country-of-origin research from the last decades: in the concept still salient in an era of global brends? Journal of Marketing Theory and Practice, Fall, vol. 13, n. 4; p. 34-45, 2005.

Peterson, Robert A. \& Jolibert, Alain J. P. A meta-analysis of country-of-origin effects. Journal of International Business Studies, 26 (4), p. 883-900, 1995.
RedRADO, Martin. Exportar para crescer. Buenos Aires: Planeta, 2003.

Reierson, Curtis C. Are foreign products seen as national stereotypes. Journal of Retailing, vol. 42, p. 33-40, 1966.

Rотн, Martin S. \& Romeo, Jean B. Matching product category and country image perceptions: a framework for managing country of origin effects. Journal of International Business Studies, vol. 23, n.3, p. 477-497, 1992.

Schooler, R. D. Product bias in Central American common market. Journal of Marketing Research. 2, p. 394-397, 1965.

SHAHID, Bhuian N. Saudi consumers' attitudes towards European, US and Japanese products and marketing practices. European Journal of Marketing, vol. 31, n. 7, p. 467-475, 1997.

Shimp, Terence A., Sharma, Subhash. Consumer Ethnocentrism: Construction and Validation of the CETSCALE JMR, Journal of Marketing Research. Aug, vol. 24, n. 3; p. 280-289, 1987.

Sohall, M. Sadiq. \& Anwar, Syed A. Insights into Malaysian consumer's perceptions of products made in the USA. The Journal of Academic of Business, Cambridge, September, p. 428-434, 2003.

Verlegh, Peeter \& Steenkamp, Jan-Benedict E. M. A review and meta-analysis of country-of-origin research. Journal of Economic Psychology, vol. 20, p. 521-546, 1999.

WANG, Chih-Kang. The effect of foreign economic, political and cultural environment on consumers' willingness to buy foreign products. Unpublished Ph.D. dissertation, Texas A\&M University, 1978.

WILSON, D.F. Why Divide Consumer and Organizational Buyer Behavior? European Journal of Marketing, vol. 37, n. 2, p. 780-796, 2000.

WHITE, Phillip D. Attitudes of US purshasing managers toward industrial products manufactured in selected European nations. Journal of International Business Studies, vol. 10, n. 1, p. 81-90, 1979.

ZeithamL, Valarie A. Consumer perceptions of price, quality and value: A means-end model and synthesis of evidence. Journal of Marketing, 52, July, p. 2-22, 1988. 